\title{
SOME PROBLEMS OF SEED PRODUCTION, COLLECTION AND DISTRIBUTION*.
}

\author{
By Carlos G. Bates
}

Seed forms the basis of all reforestation work. Upon this foundation rests both the immediate and final success of all efforts to build "artificial" forests. Considering the magnificent terms upon which we in America are prone to describe our nursery outputs and projected reforestation acreages, it is surprising that so little careful thought has been given to this most important element in true success, the use of good seed. It makes one feel that some foresters, at least, are more interested in a showing of numbers than in timber supplies of quality.

With enormous acreages of cut-over and fire-swept forest land producing nothing of value at present, and with the steadily growing public interest in the proper use of this land, active reforestation efforts threaten to grow, and are practically certain to grow to almost limitless proportions in the next few years. Already one state in the United States is producing twenty million trees for forest planting stock annually, and several others are following close behind. It is easily conceivable that in the entire United States 500 million forest trees may be planted annually by public and private agencies,- - but principally produced in public nurseries,--within a few years. One can not but wonder whether this stock will be all that it should be as the basis for building commercial forests; whether foresters as a whole are keenly alive to their responsibility to make it the best that skill can produce. I dislike extremely to be a pessimist on any subject, yet my observation has led me to believe that this enormous probable expansion can not, by present methods and present technical standards, be encompassed without the commission of grave errors; in fact, even the present scale of operations is by no means on the scientific basis it should be on.

Without seed of proper geographical origin any reforestation project may be an ultimate failure so far as valuable timber is concerned. Without a plentiful supply of seed at all times nursery and planting pperations can not be developed consistently and economically. Without seed of known quality and germinative capacity, nursery output is constantly put in jeopardy.

If we take the most aggravated case of seed price being pushed up through strong demand and lack of adequately-developed supplies, namely, Norway Pine seed at $\$ 20$ per pound, it is evident that the seed cost of producing nursery stock is only in the neighborhood of $65 \mathrm{c}$. per 1000 trees. Even this unusual figure (an average figure for coniferous stock would be nearer 10c.) however, does not measure adequately the monetary importance of seed supplies. Losses of stock, from the time of germination in the nursery beds

*Paper delivered at the meeting of the Canadian Society of Forest Engineers, Winnipeg, January 16, 1929. 
to final establishment of plantations, may be ascribed, at least in part, to poor seed, and often to seed weakened by poor handling and artificial treatment. Serious breakdown of nursery outputs due to failure of seed may cripple projected planting operations and greatly increase overhead costs by leaving men and machinery only partially employed. It not infrequently happens that seed of unknown germinative value is sown too heavily in seed-beds, overstocking of the bed results, and the trees at a given age are small, weak, and unfit for field use: they are planted, if at all, at very high cost for the numbers which succeed. Finally, seed of improper origin may appear to produce, in the nursery when first planted, stock of unusual vigor, yet after a few years this same stock may be subject to extraordinary losses from disease, frost-damage, winter-killing and similar ailments which delay if they do not totally prevent useful development into timber trees. I have made the statement, and I here repeat the charge that, largely due to the attitude of foresters that "any old seed" is good enough, and that its value is to be measured solely by the number of plantable trees that can be, obtained from it, reforestation projects in the United States are without future promise in at least 50 per cent. of the acreage so far covered. Who and what are to blame for such a serious indictment of the energetic efforts that have been made? Mainly the common American failings of "too much speed," the desire for immediate "results," and to quite a large extent an effort to make a "showing" in the matter of costs and numbers. In other words, the matter has been approached with the usual unscientific attitude of the business man "Get results and damn the particulars." But here let me say to my Canadian audience, without fear of flattery, that while I know next to nothing about the reforestation situation in Canada, I have a strong suspicion that the proverbially more conservative attitude of our cousins in all such matters has produced better results, so far as you have gone. I truly hope so. Nevertheless I feel sure that you are constantly facing somewhat the same fundamental problems, and I shall maintain that attitude throughout this discussion.

Let us, then, consider the nature of these principal seed problems: upon examination we find that they can not logically be separated under the captions of seed production, collection and distribution, which subjects merge into each other so closely that it is necessary to consider broader headings. On the one hand there are the broad questions of seed supply, and on the other those comparatively local and specific problems which bear upon seed quality and have principally to do with its nursery value. These two groups are fairly distinct and can be separately followed out.

\section{SEED SUPPLIES.}

First of all, how much do we know about the production of seed by our important tree species? Except for a very few species which have been in large demand, I doubt whether the behavior of forest trees with respect to the 
amount and periodicity of seed production could be expressed by most foresters in any tangible terms whatever. I am sure that I have only a few definite figures from which I might start to make calculations, and that if it came to making, for example, an estimate of how much seed a given area of a given kind of forest might produce in a "good seed year," most of us would fall down flatly. So far as I know, no one has ever attempted to assemble information of this kind, on American species, such as might possibly be brought together from collectors of experience and from a few experimental studies. Obviously any such information on seed crops would be of value to any agency contemplating seed-collecting operations. Besides what might be called an "historical study" of the subject, however, it is evident that there is needed even more, as an aid to seed collecting, a current information service on the prospects for immediate seed crops. As we see it, this could only be had through the co-operative reporting of a great many foresters and other competent observers, and must be of such scope as to give each year a good picture of the geographical distribution of seed supplies. The service would be designed to answer for any collector the question, "where, within the geographic and climatic range that meets my requirements, can a good crop of seed of a given species be obtained this year?" The information obtained should be available not only to those who co-operate in obtaining it, but to all others who desire it. I may say that such a survey is one which the Lake States Forest Experiment Station intends to undertake immediately, at first in a somewhat local way, but later, we hope, more comprehensively, and I take this occasion to solicit the aid and co-operation of Canadian foresters whose territory is adjacent to that in which we are principally operating. We expect shortly to circularize all of our neighbors from whom we might possibly expect to obtain help. To make such a survey country-wide would be a task requiring the co-operative efforts of all the seed users in the United States and Canada, and of as many other foresters and naturalists as possible.

There is a special phase of this task of locating and reporting seed supplies which, at least from the standpoint of my personal hobby, deserves strong emphasis. This is the obligation to locate and to bring into utilization the available stands of most desirable character for seed production; an obligation which, it seems to me, every forester should take upon himself. Admittedly, there may be at this stage considerable doubt as to what characteristics make a stand desirable for seed production, but it seems to me that the outstanding fact in the forest seed traffic to-day is that seed is usually collected from the poorest trees that could possibly be found, mainly because that is the easiest way to obtain seed. If the trees from which seed is commonly taken are not inherently poor, at least they are quite generally young, undeveloped and untried by the long natural struggle for existence; we simply 
do not know what they may "turn out" at' maturity, or how soon they may succumb to some weakness*. If we believe in the laws of heredity only in the broadest sense, we must admit that the present common practice means no good for the quality of our planted forests. The obvious remedy for this situation is to obtain seed, just as far as possible, from mature or welldeveloped trees which have survived against enemies and competitors, and which at maturity have developed desirable timber characteristics. To utilize mature virgin stands, most of whose individuals have creditably stood the test, is a plain necessity; to improve such stands through the elimination of the occasional tree which has attained dominance but which has undesirable characters as a timber tree, is a further refinement of the same process. This is a subject which I have treateed in a special article $\dagger$ and shall not elaborate upon here. The collector who desires to go to the extra pains to obtain seed of proven parentage, should be favored in every way possible, and while we may individually know of desirable seed stands which we prefer to reserve for our own needs, there are doubtless many others which are not being utilized at present, concerning which information might well be put in circulation.

Obviously the efforts along this line, which we may recommend broadly without question, could be greatly strengthened and encouraged by the certain knowledge that the stock grown from a given seed-source is of superior quality. In other words, we need a great many so-called "progeny tests" in which, by developing seedlings under identical conditions, the relative worth of the seed from a great many sources is given experimental trial. Such tests may be both 'geographic' and 'parentage' tests, and may involve both trials and seed from different portions of a tree's range, to determine their suitability under specific conditions of climate and soil, and seeds of different parents in the same general locality. Because of the importance of the phase of climatic adaptation, no one central agency can undertake such tests except as applying to a limited region. However, I believe, that just as the Union of (European) Forest Experiment Stations undertook, about 1900, to see through such tests for the geographical strains of the important forest trees of Europe, so also we may infer that a general co-operative interest and effort is needed to provide the means by which such tests may be comprehensively made in America. This really is an international problem, for the experiments conducted in Europe, though far from maturity, have already resulted in restrictions upon the indiscriminate traffic in seeds. It may appear an unpleasant thing to say, and no doubt certain commercial interests will object

*Discussion of this subject brought out that these young trees might be the progeny of excellent forest trees formerly growing on the site. Well and good if the young trees started from the seed of the mature dominants, but not if they sprung from the poor, suppressed trees left when the area was logged. Author.

†“Tree Seed Farms," Journal of Forestry, XXVI, 8; December, 1928. 
to my saying it, but it is, nevertheless, altogether probable that we in the United States have a right to look with suspicion on most Canadian forest tree seed, and you have an identical right to demand the use in Canada of "home grown" seed. There are undoubtedly many cases in which seed may be sent across the border with no harm whatever, but almost certainly the general outcome of a better knowledge of the matter will be to restrict the transport of seed to comparatively short distances. North-and-south movement of seed especially must be discouraged, since it results in attempts to grow trees under unaccustomed temperature conditions, and according to Swedish experience with pine, even a very small difference in the temperature of the growing-season may have striking effects upon the success of plantations*. It seems probable that we shall ultimately lay out our traffic lanes for seed essentially along isothermal lines. The obvious immediate need is to make each natural forest district as nearly self-supporting in the matter of seed supplies as is possible.

There is one further point in this connection which I would mention as accentuating the need for co-operative effort. This is the difficulty of obtaining the materials for such comprehensive tests as I have described, from a great variety of sources. If there were one general agency interesting itself in such problems as this it would, almost as a matter of course, have access to a great many seed samples of most of the important species, from which such materials as would have experimental value could be selected. It would, moreover, have contact, such as few of us now possess, with a great many collectors and possible collectors. It would, therefore, not only be in a position to suggest to individual agencies important tests that might be undertaken, but also be able to supply much of the needed materials for the tests.

But, if we can not have at once all of the carefully-devised experiments that are needed for scientific proof of the questions of heredity and climatic adaptation, there is one thing which we might begin to do at once, which should have been under way for the past twenty years, and which would throw a great deal of light on the subject. This thing is for every public nursery to keep adequate records of the sources of seed which it uses. This is a matter of self-interest; how, otherwise, may any reforestation expert or director know the real cause of the success or failure of a forest plantation? He may, it is true, carry a certain amount of such information in his head; if the plantation turns out well he will be well-informed on the reason; if it turns out badly he may easily forget that it was he who ordered a certain lot of seed from a far-distant source many years ago. I hardly think it wouldl be fair to assign these ulterior motives as the cause for the almost complete

*Oeneroth, for example, estimates a depreciation in plantation values at age 10-15 of about 35 per cent. if the seed is planted in a site varying by $1^{\circ} \mathrm{C}$ from the summer temperature of its natural habitat. Swedish "Tidskrift" 1926, H. 5-6. 
lack of seed-source records for the plantations in the United States, but I do know from personal experience that, with a few exceptions, such records have not been kept effectively in the past. Sometimes it is lack of coordination betwteen plantation and nursery records which is at fault, but more often we find that even before stock has left the nursery the record of its source has been lost except as some employee may remember something about it. Admittedly, to keep such records for every bed of a large nursery is some task, and to see that this record is transferred to every field plantation might be practically out of the question, but it should at least be possible to brand correctly each year some of the larger and important plantations made in each state and province. It seems to me that every public agency connected with nursery production should be made to see the need and importance of this. I may say that the U.S. Forest Service has worked out a card system for records covering this point, which is quite satisfactory if the records are kept conscientiously. It is, however, the substance and not the form in which we are interested. I feel quite sure that when these records have been kept for a few years, there will be a great many more converts to the belief that the source of seed is of the utmost importance to truly successful reforestation.

It is apparent, then, that there are problems of large magnitude involved in the matter of seed supplies. A better general knowledge of the amount and periodicity of seed crops would permit any seed collector, but especially the director of the large nursery, to plan his collecting a number of years ahead, and thus would avoid the oft-recurring necessity of going into the general market and accepting seed of unknown or undesirable origin, at high prices, in order that the planned output of his nursery may be maintained. This general knowledge should be supplemented by current information on the occurrence of seed crops, of such scope that the individual collector may determine at what point he would best seek seed for his particular needs. Next in order of importance are the problems of the indiscriminate traffic in seeds, which can largely be eliminated by efforts to collect seed in a greater number of places, which will make each natural forest district selfsustaining as to its needed seed supplies. Problems involving the substitution of better seed for the "mongrel" stock which now enters so largely into "the trade" and also into large reforestation projects, are, unfortunately, not so readily attacked by direct methods, although, if the uncommon "common sense" is used, and the best stands are utilized for seed production as far as possible, a long step forward will have been taken. This phase of our problems, more than any other, requires experimental evidence, for the simple reason that we do not know with any certainty what kinds of defects in trees may taint their progeny. Until these problems are worked out experimentally, the safe procedure is to avoid all defective trees in seed collecting. 


\section{SEED QUALITY:}

Let us clearly distinguish between the problems which bear upon the source of seed, and the obtaining of desirable supplies,, and those of more narrow scope which may affect the quality of the seed-primarily the germ. inative quality, after the seed is collected, for the most part.

Before entering upon the latter group of problems, I wish to bridge the gap with this thought, if I may do so without causing confusion: If we insist too strongly upon having for our nurseries seed of the highest quality, and if the nurseryman is permitted to gauge the value of the seed which he obtains by its immediate showing in the form of large, sturdy nursery stock, I fear we shall not get far toward our objective of obtaining better and, in the long term, more successful plantations. To illustrate this point, let me say that it can almost be guaranteed to any nurseryman in the north that he may have larger nursery stock at a given age by going as far south as possible for his seed supply. And, if this nurseryman is very careful about the winter mulching of his seed-beds, he may even be able to bring this large stock, from large seeds, to the planting age without its weakness having become apparent. But we know too well that this rapidgrowing stock is not suited to the northern climate, and while it may escape injury for several seasons after planting, sooner or later it will succumb under the extreme test that the climatic conditions provide. Of course, some species are much more hardy over a wide range of conditions, than are others, but in general the nurseryman's ideal of the biggest trees in the shortest time must not be the criterion by which seed of a given source is approved or disapproved.

There is still another phase of this apparent conflict between true "aristocracy" in seed and the vigorous "upstart" which is likely to be the nursery. man's pride. This conflict arises from the fact that in choosing the best forest trees for seed production we shall be guided almost wholly by evidence which reflects the vegetative development of the tree, while the conditions of nutrition which might make the tree a good seed-producer are in an entirely different category. It, therefore, follows that the best trees in the forest are quite often poor seed-producers, as is commonly known, and this may even extend to the point where their seed is somewhat lacking in germ. inative vigor. On the other hand, the open-grown tree or the scrubby tree whose vegetative development has for some reason been arrested, is likely to be both a copious and vigorous seed-producer, and this is the reason for its being "picked upon" so often for cheap supplies of seeds. These facts make it plain that ordinarily, good seed cannot be cheap seed, in the first cost or even in the cost at the end of the nursery period, although it may be much the more profitable to use in the long run. It seems to me best that this should be recognized at the outset. Neither cheapness of seed nor 
its immediate showing in the nursery are safe criteria of its suitability for a particular end.

Considering, now, that we have or contemplate a collection of seed, whether it be good, bad or indifferent as to origin, it is obvious that we must strive to maintain its viability at as high a point as possible until the seed has been sown in the nursery, and we then wish to obtain as prompt and vigorous germination as possible. It is evident, then, that questions of viability are involved in every operation from the actual gathering of the seed until it is sown, perhaps several years later. I shall enumerate the problems involved in these processes rather briefly, since they are of comparatively simple character, although very much inter-related one to another.

1. The problem of the season of collecting. Do we know when seed should best be collected? Is it a safe general rule that seed should only be collected when it becomes dry upon the tree, or when it falls naturally? Just how important is the ripening process which may continue as long as the seed maintains a moisture connection with the tree, or as the result of certain temperature exposures which it receives in the natural state? And should the ripening process be the same if we expect to use the seed at the earliest cpportunity, as it would be if we expected to store it for a number of years?

Obviously each American species presents different problems in this phase of its treatment, and different climatic conditions for the same species may also introduce different problems. There is a lot of empiric knowledge on these subjects which is doubtless very valuable. But that we know very little about them, of an exact nature, and that our practices may often be far from ideal, is quite evident. I learned recently from a Norwegian forester that the Norwegians do not attempt to collect Scotch pine cones until about February. There is obviously some difference between Scotch and, for example, Norway pine cone developments, but it seems to me that this conclusion as to Scotch pine seed-ripening, based on long experience and innumerable tests, should warn us against being unnecessarily hasty in any case. I have reason to know that in northeastern Minnesota Norway pine cones, obtained in June after their maturity, may still yield a good quantity of desirable seed, and there is scarcely any doubt that in the northern-most part of the range of this species most of the seed is held in the cones until the warm weather of spring, at least after cool growing. seasons. Before I had had any personal experience with this species I was told that cones were "ripe" and might be collected in Northern Minnesota at any time after the 20th of August or possibly the 1st of September. This earliest date undoubtedly varies considerably from year to year. I found that cones were still in a very green state on the 9th of September, 1928, and while viable seeds were obtained at this time, at least the collection showed, by its delayed germination, the need of after-ripening, and I question whether such seeds will retain their vitality well. Much farther south, I found cones 
actually ripe, that is, beginning to dry and open, about the 1st of October, and even as late as October 21st opening had not proceeded far enough to permit any appreciable loss of seeds.

When cones are cut by squirrels, a different situation is evidently presented, but even here is it not likely that permitting the cones to ripen, under the conditions in which the squirrels so carefully store them, would be beneficial? I think so, for the simple reason that the squirrels are extremely canny about maintaining the seed in perfect condition.

2. The immediate disposal of seed after collecting is in many cases a very important problem. In some cases this may mean placing directly in storage for the winter, or longer, while in other cases is meant merely temporary disposal pending such cleaning or extraction operations as the particular seed may require. I shall not attempt to go into detail as to the nature of the problems here encountered, for they are extremely varied, but I wish to put forth the idea that the treatment in this period, which may be called the "period of after-ripening" is essentially a drying process. I am of the opiinion that if we had more definite terms in which to express the degree of dryness which is attained by seeds or should be for the best results, the entire series of processes could be placed on a more scientific basis, and empiric information on these processes, which is so varied and confusing to the novice, could be reduced to comparatively simple terms. For this reason, some experimental work along the line which is now being conducted at the Lake States Forest Experiment Station has been placed on the basis of drying in atmospheres of known humidity, the result being a definite condition of the seed instead of a wholly problematic condition. This same idea might well pervade the discussions of extracting treatments such as are used with many coniferous seeds, and of the states of preparation in which seeds should be placed in storage, except in those cases where desirable storage conditions seem to imply a quantity of free moisture, such as that of damp sand.

The after-ripening process, however, is not entirely one of drying, for it has been found, for example, that spruce seed may be after-ripened and its immediate germination greatly stimulated by the use of heat, while with most of the stony pits of fruits and the hard-shelled seeds, exposure to low tem. peratures has some beneficial effect of a chemical or mechanical nature. These examples, and that of lodgepole pine, which the writer has shown to be benefited by heat in addition to that required for extraction, merely serve to show the variety of the problems involved when we consider the whole field of tree seeds, and the necessity of systematizing and extending present knowledge.

3. Extracting processes for coniferous seeds, which usually involve a hastening of the natural rate of cone drying through the use of artificial heat, are so closely related to the problems just mentioned that it is hardly neces- 
sary to consider them separately. Their importance lies in the fact that seeds of high quality are very often over-cooked and their usefulness destroyed. Often the effect of overheating is not so apparent if the seed is sown at once, since the embryo itself seems to be fairly resistant, but if these same seeds are kept for long their fatty elements become rancid and a general disintegration sets in. That the empiric practices in the extraction of coniferous seeds are often far from the ideal is shown by the wide variation in the character of the processes in use. Extraction kilns vary from stoveheated rooms with practically no ventilation to flue-like structures through which currents of hot air are forced mechanically. In the one case a sort of steaming treatment of cones is effected, with drying resulting .only gradually from the effects of high temperature; in the other drying may be so rapid that the cones are themselves kept far below the temperature of the air-current. Without attempting to state which kind of drying process may be the less injujrious to seed, it is evident that for the treatment of a given species, there is a considerable variety of processes to choose from, and that there is an optimum combination of direct temperature effects and of rate of drying, for each species, at which the viability of seeds will be least affected. It is also evident that the character of treatment that seeds can best stand depends very much on their state of ripening and moisture condition at the outset, and it is probably this variable which leads to such discordant results as are often reported. All of which simply means that seed extraction at the present time is likely to be very much a "hit-or-miss" process.

4. Storage of Seeds: The relation of the condition of the seed to its keeping qualities has already been mentioned in connection with natural and after-ripening. This is probably a very important phase of the question of storage, but heretofore the study of the keeping of seeds for long periods, as is often necessary with those species which bear good crops infrequently, has been directed almost entirely to an examination of the physical conditions of the storage environment. These conditions are important, and need much further study than has been given them, especially for the more perishable of the tree seeds, but it may as well be said that any study of storage conditions which does not take into account the varying degrees of ripeness and dryness at which seeds may go into storage, is incomplete and essentially worthless. In a complete study of storage the entire history of the seed from the time of its collection-and even the history of its growthis important, and without doubt all controllable phases of this history must be brought into balance to obtain the best results in storage.

5. Finally we come to pre-treatment for sowing, such as is necessary with some seeds whose seed-coats are naturally resistant to moisture, or seeds which for some reason are not readily "awakened" from dormancy. As a matter of fact, all of the seed-handling processes that have been mentioned are "pre- 
treatments" affecting dormancy. White pine seed presents a good example of a complicated problem of this sort. Regardless of its age, white pine seed is never given to prompt, spontaneous and even germination, but the different seeds of any given lot may germinate over a period of ninety days or more. The seriousness of this germinating habit lies in the fact that favorable nursery conditions for germination must be maintained for such a long period to secure the full value of the seed, and that the seedlings at the end of the first or second growing-season are so uneven-aged as to vary greatly in size. Furthermore, because of this peculiarity, it is often difficult to obtain a satisfactory germination test indicating how heavily the seed should be sown to obtain desired numbers of plants. The difficulties of uneven germination in seed-beds are largely, if not wholly, overcome by fall sowing, which permits the seeds to become thoroughly soaked before temperatures conducive to germination occur. Possibly, also, the freezing processes effect chemical changes in the seeds. Since fall sowing is not always feasible, the problem remains as to how similar results can be obtained with spring sowing. While many attempts have been made with various species of the 5-needled pines, to solve this problem, it may be said that it has not yet even been clearly shown whether we are dealing with a condition of seed-coat impermeability or of seed dormancy. In greater or less degree similar problems of partial or general delay in germination, occur with nearly all species, so that here alone is a vast field for those inclined toward laboratory experimentation.

\section{SEED SUPPLY "REGULATION" VERSUS VOLUNTARY CO-ORDINATION}

From this survey of the field, which has been by no means exhaustive, I think it should be apparent that there are enough problems involved in the best treatment of seed and in the use of the best seed to keep an army of investigators busied for many years. Merely to mention some of the problems of the traffic in seed, which require attention before reforestation efforts may be said to be upon a safe and substantial basis, should be sufficient to point to the need for a concerted effort by Canadian and American foresters for their solution, and for such co-operative committments as may be necessary for the regulation of seed supplies. Frankly, we feel that some form of regulation is as necessary at this time in America as it has been proven to be in several of the European countries where forestry plays an important economic part. Why should we wait until vast areas in our countries have been reforested at needless expense, and with many failures which can honestly be ascribed only to our own shortcomings: why should we permit ourselves to become the laughing-stock of anyone who cares to take up cudgels against the profession, before admitting this need? Is it because we do not know where to begin, or because in these democratic countries we hesitate at anything which suggests of the individual, interfer- 
ence with "business" or abridgment of personal liberties? I admit a certain reticence on the latter account: I am constitutionally opposed to any form of legislative moralizing. But this very objection imposes upon me certain obligations as an individual, and I sincerely believe that the forestry profession is intelligent enough, big enough and strong enough to recognize its obligation in the matter at hand, so that we shall not have to be dictated to by law. makers.

What is plainly needed, then, to set the forces of the profession at work to control the seed situation along sane and scientific lines, is a voluntary organization of the seed-using agencies, and a central clearing-house to represent them, which, for lack of a better name, we may at this stage call a "seed control station." This situation would have, primarily, information gathering and disseminating functions, but I feel sure that it would also in a short time develop an important position in making routine tests of seed, in settling questions of identity and quality, in conducting or at least sug. gesting and supervising special researches on seed, and perhaps to some extent serving as a central exchange for quantities of seed. The functions which might develop for such an agency may, I feel sure, best be left for your imaginations to picture. But I believe that anyone who gives these matters careful thought will come to the same conclusion that we have reached, namely, that a large amount of educational work is needed (including the education of many practicing foresters); that only an agency which has the strong support of those engaged in the seed traffic can bring together the present available information on seed which is widely scattered among in dividuals and institutions; and that before anything in the nature of legislative "regulation" of seed supplies is talked of, it is the solemn duty of foresters to determine what can be accomplished toward the same end and toward mutual benefit by a democratic, co-operative effort. If even the more specific scientific and technical problems that I have enumerated are left to desultory, individual research workers, only a few of the most outstanding of these problems are likely to be attacked in the next quarter-century. But if some large group, whose interests lie largely in this field, co-operate to bring the subject to the front, and to provide for the bringing together and correlating of existing knowledge and the direction of research along lines which will be most effective, it would seem to me that the accomplishment might be many times as great, and that the benefit to the reforestation enterprise, particularly the large-scale public enterprises in which scientific method might count so largely, would many times repay the cost of the individual effort that would be required.

The banding together, under whatever form of organization may appear most desirable, of those public agencies, commercial dealers and nurseries who are engaged in the collection and use of forest tree seeds and to whom the problems of seed are of some vital concern, would make 
